\title{
PERAN FP KIBBLA SEBAGAI UPAYA PEMBERDAYAAN MASYARAKAT DI KABUPATEN CIREBON
}

\author{
Khusnul Khotima \\ Mahasiswa Psikologi Pendidikan Islam (PPI) \\ Pascasarjana IAIN Syekh Nurjati Cirebon \\ Emai: khusnulkhotimah1106@gmail.com
}

\begin{abstract}
ABSTRAK
Fenomena maraknya kematian ibu dan anak bayi baru lahir menjadi hal yang perlu untuk diperhatikan. Hal tersebut disebabkan kurangnya pengetahuan akan hal-hal terkait kehamilan bagi ibu, terutama di wilayah yang sulit tersentuh informasi. Fenomena tersebut menjadi alasan pentingnya pengadaan sosialisasi bagi kaum perempuan, terutama bagi calon ibu. FP KIBBLA Kabupaten Cirebon adalah salah satu lembaga kemasyarakatan yang peduli akan pentingnya pemberian informasi dan pengetahuan tentang kehamilan bagi masyarakat. Salah satu program yang telah dicanangkan adalah program EMAS dan MAMPU.
\end{abstract}

Kata Kunci: FP KIBBLA, Program EMAS, Program MAMPU

\begin{abstract}
The phenomenon of the rampant death of mother and newborn baby child becomes a matter that need to be paid attention. This is due to a lack of knowledge about pregnancy-related matters, especially in areas that are hard to touch with information. The phenomenon is the reason for the importance of socialization procurement for women, especially for prospective mothers. FP KIBBLA Kabupaten Cirebon is one of the social institutions concerned about the importance of providing information and knowledge about pregnancy for the community. One of the programs that has been announced is the program of EMAS and MAMPU.
\end{abstract}

Keywords: FP KIBBLA, EMAS Program, MAMPU Program

\section{A. Pendahuluan}

Masyarakat Cirebon adalah masyarakat yang kehidupannya banyak didukung oleh sistem kepercayaan dan agama. ${ }^{1}$ Hal tersebut terlihat dengan adanya berbagai upacara-upacara adat yang dilakukan oleh masyarakat, seperti upacara bagi kesuburan bumi, panjang

${ }^{1}$ Raji, t.t, Selamatkan Ibu, Sehatkan Anak, Data Skunder, Cirebon: FP-KIBBLA, Hlm.7. jimat, ngunjung buyut, sedekah bumi, nadran, dan lain sebagainya. Selain adanya fenomena akan sistem kepercayaan dan agama tersebut, Cirebon, khususnya Kabupaten, terdapat berbagai isu strategis. Salah satu isu tersebut adalah adanya kematian ibu dan bayi yang baru lahir.

Tingkat permasalahan angka kematian ibu yang melahirkan dan bayi 
yang baru lahir serta anak menjadi sangat serius untuk diperhatikan. Fenomena kematian ibu dan bayi serta anak tersebut merupakan sebuah tragedi yang terus terjadi di kalangan masyarakat di negeri ini. Untuk itu, diperlukan penanganan yang serius dalam menekan angka kematian ibu dan bayi serta anak tersebut. $^{2}$

Melihat fenomena yang terjadi di masyarakat tersebut, pemerintah telah melakukan berbagai upaya untuk menurunkan kematian ibu, bayi baru lahir dan anak. Seperti adanya pendelegasian bidan di setiap desa, menyediakan fasilitas kesehatan Pelayanan Obstetri Neonatal Emergency Dasar (PONED) di puskesmas seta Pelayanan Obstetri Neonatal Emergency Komprehensif (PONEK) di Rumah Sakit. Selain itu, pada tahun 2011, pemerintah mencanangkan program Jaminan Persalinan (Jampersal) yang diperuntukkan bagi seluruh ibu hamil, bersalin dan nifas serta bayi baru lahir yang belum memiliki jaminan kesehatan atau asuransi kesehatan. Adanya program tersebut diharapkan dapat memberikan kontribusi dalam upaya pencapaian penurunan angka kematian ibu dan bayi baru lahir serta anak. $^{3}$

Dalam hal ini, pemerintah daerah pun memiliki komitmen untuk mendukung program dalam menekan angka kematian ibu dan bayi baru lahir serta anak. Salah satunya yang telah dilakukan oleh pemerintahan daerah Jawa Barat, yakni kabupaten Cirebon melalui Forum Peduli Kesehatan Ibu Bayi Baru Lahir dan Anak (KIBBLA).

\section{B. Sekilas Tentang FP KIBBLA Kabupaten Cirebon}

Forum Peduli Kesehatan Ibu, Bayi Baru Lahir, dan Anak (KIBBLA)

\footnotetext{
2 Wawancara dengan Pak Raji, Ketua Forum Peduli KIBBLA, Pada Selasa, 17 November 2015.

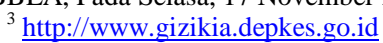

Kabupaten Cirebon terletak di Sumber. Forum ini lahir dari kepedulian sejumlah organisasi masyarakat (civil society) terhadap masih tingginya angka kematian ibu (AKI) dan angka kematian bayi (AKB) di Kabupaten Cirebon. ${ }^{4}$ Forum ini merupakan salah satu forum yang melaksanakan program Expanding Maternal and Neonatal (EMAS) dan bekerjasama dengan USAID. Program EMAS bertujuan untuk menurunkan AKI dan AKN di Indonesia sebesar $25 \%$ dengan meningkatkan kualitas dan akses kegawatdaruratan yang setara. Program EMAS dilaksanakan di enam Provinsi yang berkontribusi terhadap $50 \%$ kematian ibu dan bayi di tingkat nasional. Salah satunya adalah Kabupaten Cirebon. Program EMAS yang berjangka waktu 5 tahun (20122016) bertujuan untuk mempercepat penurunan AKI dan AKN melalui pendekatan klinis dan penguatan sistem rujukan yang efektif dan efisien di Rumah Sakit dan Puskesmas.

Forum Peduli KIBBLA menyadari bahwa peran masyarakat sangat strategis dalam hal ini melengkapi peran pemerintah dan stakeholder lainnya. Karena yang telah diketahui bahwa Angka Kematian Ibu dan Bayi Baru Lahir (neonatus) di Indonesia memperlihatkan

Kabupaten Cirebon belum memiliki Angka Kematian Balita (AKABA), sehingga sebagai acuan dipakai AKABA Provinsi Jawa Barat, dari tahun ke tahun menunjukkan penurunan tetapi masih berada di atas angka nasional, yaitu 132/1000 kelahiran hidup (1986), 105/1000 kelahiran hidup (1992), dan 64.67/1000 kelahiran hidup (2000). Berdasarkan survey yang dilakukan oleh BPS, ada lima penyebab kematian balita (umur 14 tahun) terbesar di rumah sakit di

\footnotetext{
4 Wawancara dengan Pak Raji, Ketua Forum Peduli KIBBLA, Pada Selasa, 17 November 2015.

${ }^{5}$ Raji, t.t, Selamatkan Ibu, ..., Ibid, Hlm. 1-2.
} 
wilayah Kabupaten Cirebon tahun 2015 adalah Demam Berdarah 14 (17.1\%), Bronchopnemonia 13 (15.9\%), Meningoenchephalitis 7 (8.5\%), Meningitis 7 (8.5\%), dan Sepsis 5 (6.1\%). Angka tersebut tanpa membedakan pasien dalam dan luar wilayah Kabupaten Cirebon. ${ }^{6}$

Angka Kematian Ibu (AKI) menggambarkan representatif nasional dan merupakan salah satu indikator derajat kesehatan masyarakat. Angka Kematian Ibu Provinsi Jawa Barat berdasarkan hasil SKRT tahun 1992 adalah 425/100.000 kelahiran hidup, dari hasil survey tersebut diketahui jumlah kematian ibu terbesar terjadi pada saat melahirkan. Sedangkan berdasarkan SKRT tahun 1995, AKI Nasional 373/100.000 kelahiran hidup. Menurut pemetaan AKI di Jawa Barat berdasarkan survey AKI 2003 BPS Provinsi Jawa Barat menunjukkan AKI terbesar di wilayah Pantura dan Cirebon (Indramayu, Cirebon, Majalengka, dan Kuningan) sebesar 366.80/100.000 kelahiran hidup, sedangkan yang terkecil di Bandung Raya dan Bodebek (Bogor, Depok, dan Bekasi), yaitu 296.17/100.000 kelahiran hidup.?

Angka Kematian 228/100.000 kelahiran hidup dan Angka Kematian BBL 18/1000 kelahiran hidup pada SDKI 2007 yang lalu. ${ }^{8}$ Pada SDKI 2012, Angka Kematian Ibu Provinsi Jawa Barat 359/100.000 Kelahiran Hidup. $^{9} \quad$ Kondisi ini masih cukup mengkhawatirkan mengingat untuk mencapai target MDGs pada tahun

\footnotetext{
${ }^{6}$ Profil Kesehatan Provinsi Jawa Barat dalam Rencana Strategi Kesehatan Kabupaten Cirebon, Artikel, Cirebon: Dinas Kesehatan, 2014,

http://dinkes.cirebonkab.go.id/wp-content/uploads/ReviewRenstra-2014-2019.pdf, Diakses Pada Minggu, 22 Juli 2018. HIm. 31-32.

Hlm 29.

${ }^{7}$ Profil Kesehatan Provinsi Jawa Barat, ..., Ibid,

${ }^{8}$ Sudibyo Alimoesa, 2012, Angka Kematian Ibu, 228/100.000 Kelahiran Hidup, Artikel, Banjarmasin: Kompas, https://tecno.kompas.com, Diakses Pada Minggu, 22 Juli 2018 Hlm 29.
}

2015, masih diperlukan akselerasi kegiatan agar target AKI yang diluar jalur. Begitu pun dengan kondisi di Kabupaten Cirebon. Hingga April 2015, angka kematian ibu saat persalinan di Kabupaten Cirebon 28 orang. Sungguh menjadi pemicu bagi semua komponen masyarakat untuk turut serta.

kematian tersebut memerlukan keterlibatan banyak pihak tidak terkecuali organisasi masyarakat sipil (civil society). Adapun pihak-pihak yang terlibat dalam upaya pelaksanaan penekanan angka kematian ibu melahirkan, bayi baru lahir, dan anak adalah Nahdlatul Ulama (NU), Muslimat, Fatayat NU, GP Ansor, Muhammadiyah, Aisyiyah, Nasyiatul Aisyiyah, Pemuda Muhammadiyah, AlWasliyah, Muslimat Al-Wasliyah, Tim Penggerak PKK, Koalisi Perempuan Indonesia (KPI), LSM Warga Siaga, Asosiasi BPD, Forum Komunikasi Kuwu Cirebon (FKKC), Karang Taruna Kabupaten Cirebon, Forum Tenaga Kesejahteraan Sosiall Kecamatan (TKSK), Lembaga Perlindungan Anak (LPA), KNPI, PKBI, Dewan Kesenian Kebudayaan Cirebon, HU Fajar Cirebon, HU Radar Cirebon, HU Kabar CirebonCirebon, Radar Cirebon TV, HU Rakyat Cirebon, www.cirebonnews.com, dan RRI Cirebon. ${ }^{10}$

Salah satu upaya yang telah dilakukan oleh forum tersebut adalah dengan membentuk sekolah bagi ibu hamil. Sekolah ibu hamil ini berfungsi untuk memberikan pengetahuanpengetahuan terkait dengan kehamilan kepada para ibu hamil. Upaya ini dapat membantu dan membuka pola pikir masyarakat di desa, khususnya para ibu hamil. 


\section{Peran FP KIBBLA sebagai Upaya Pemberdayaan Masyarakat di Kabupaten Cirebon}

Seperti yang telah dipaparkan sebelumnya bahwa FP KIBBLA ikut andil dalam upaya pemberdayaan masyarakat di Kabupaten Cirebon. Dalam pelaksanaannya, FP KIBBLA pun dibantu oleh berbagai organisasi masyarakat yang peduli terhadap kesehatan ibu bayi dan bayi baru lahir serta anak. Salah satunya adalah organisasi perempuan Muhammadiyah (Aisyiyah) melalui program EMAS dan MAMPU. ${ }^{11}$

\section{Program EMAS}

Berbagai upaya Penurunan Angka Kematian Bayi (AKB) dan Angka Kematian Ibu (AKI) semakin gencar dilakukan dalam upaya peningkatan kualitas kesehatan di Indonesia. Salah satu program yang dilakukan untuk menurunkan AKI dan AKB adalah adanya Program EMAS (Expanding Maternal dan Neonatal Survival) yang mendukung pelaksanaan kegiatan forum KIBBLA. Salah satunya dilaksanakan di Kabupaten Cirebon Provinsi Jawa Barat, tepatnya di Kecamatan Sedong.

Program EMAS yang dilaksanakan di Kecamatan Sedong mencakup 10 desa, di antaranya sebagai berikut. ${ }^{12}$
a. Desa Karanguni
b. Desa Winujaya
c. Desa Putat
d. Desa Sedong Lor
e. Desa Sedong Kidul
f. Desa Panongan
g. Desa Panongan Lor
h. Desa Penambangan
i. Desa Kertawangun
j. Desa Winuhaji

Ibu hamil merupakan sasaran utama dalam forum KIBBLA karena masalah kehamilan adalah hal yang sangat penting untuk diperhatikan demi mengurangi kematian ibu dan bayi baru lahir. Kegiatan khusus ibu hamil dalam forum KIBBLA bersumber pada program EMAS yang telah direalisasikan di Kecamatan Sedong adalah SMS Bunda. ${ }^{13}$ Kegunaan SMS Bunda ini yaitu untuk memberikan seputar informasi kesehatan dari masa kehamilan sampai melahirkan. SMS bunda ini disosialisasikan dengan cara kader ataupun bidan desa diberikan tugas utuk mengumpulkan data jumlah ibu hamil beserta nomer telepon atau handpone ibu hamil, kemudian dari pihak pusat forum KIBBLA menyebarkan SMS bunda pada semua nomer yang sudah terdata.

Selain SMS Bunda adapula kegiatan kelas ibu hamil yang dilaksanakan setiap 3 bulan sekali dalam setiap tahunnya. Materi pembahasan dalam kelas ibu hamil bertujuan untuk memberikan pengetahuan sebagai suatu bentuk penanggulangan ibu hamil dan anak yang beresiko tinggi di antaranya sebagai berikut. ${ }^{14}$
a. Tanda-tanda awal kehamilan
b. Batas normal berat badan ibu hamil
c. Mitos-mitos dalam kehamilan
d. Impeksi organ reproduksi pada masa kehamilan ataupun penyakit yang dapat menyerang ibu hamil
e. Senam ibu hamil
f. Tanda-tanda masa persalinan
g. Tanda-tanda ibu hamil dan anak baru lahir yang memiliki resiko tinggi

11 Wawancara dengan Pak Raji, Ketua Forum Peduli KIBBLA, Pada Selasa, 17 November 2015.

12 Wawancara dengan Pak Raji, Ketua Forum Peduli KIBBLA, Pada Selasa, 17 November 2015.
13 Wawancara dengan Ibu Istiqomah, Ketua Aisyiyah Kota Cirebon, Pada Senin, 02 November 2015.

14 Wawancara dengan Ibu Istiqomah, Ketua Aisyiyah Kota Cirebon, Pada Senin, 02 November 2015. 
h. Batas masa nifas pasca melahirkan dan lain sebagainya yang berkenaan dengan informasi seputar kesehatan ibu hamil dan melahirkan.

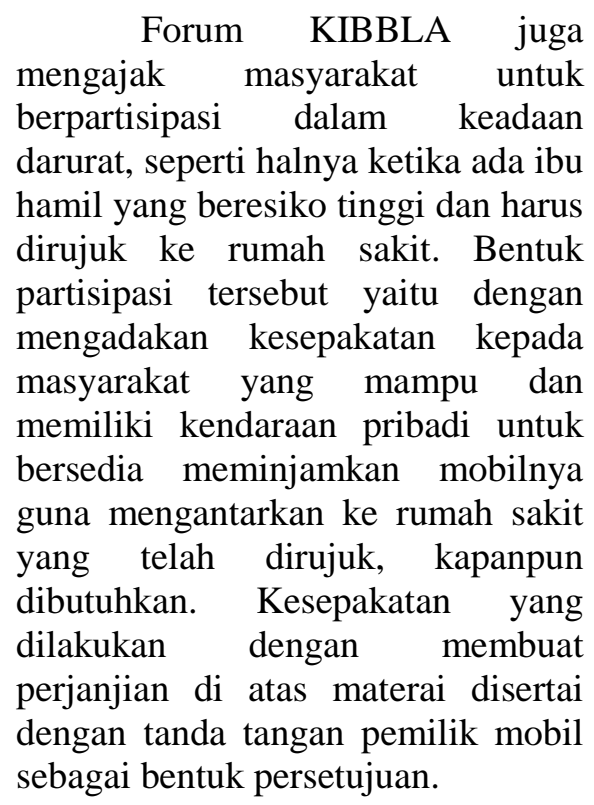

2. Program MAMPU Program MAMPU merupakan program yang diluncurkan oleh USAID yang bekerjasama dengan pemerintah Indonesia untuk meningkatkan kesehatan reproduksi bagi perempuan. Program ini sudah berjalan selama satu tahun. Sasaran program ini tidak mencakup seluruh masyarakat, melainkan hanya Pasangan Usia Subur (PUS) yang memang benar-benar tidak mampu. Adanya program MAMPU di kabupaten Cirebon dikarenakan kabupaten ini merupakan kabupaten yang besar dan jumlah masyarakatnya masih banyak yang dibawah rata-rata.

Beberapa organisasi maupun lembaga yang ikut hadir dalam komitmen baru forum peduli KIBBLA salah satunya adalah organisasi Muhammadiyah yang bernama Aisyiyah. Dalam pelaksanannya, organisasi perempuan Muhammadiyah (Aisyiyah) yang menjadi koordinator dalam program tersebut. $^{15}$ Setiap organisasi yang ikut dalam forum KIBBLA memiliki program masing-masing yang berkomitmen untuk menurunkan Angka Kematian Ibu (AKI) dan Angka Kematian Bayi (AKB). Selain itu, bertujuan untuk memberikan kesadaran kepada masyarakat akan pentingnya kesehatan pada masa kehamilan, melahirkan, pasca melahirkan dan kesehatan reproduksi.

Kegiatan yang dilakukan dalam program MAMPU terkait aspek-aspek tersebut di antaranya sebagai berikut. ${ }^{16}$

a. Air Susu Ibu (ASI)

Pelaksanaan pada aspek ASI dengan melakukan sosialisasi pentingnya pemberian ASI eksklusif selama 6 bulan tanpa makanan campuran lainnya, karena pada bayi baru lahir memiliki lambung sekecil kelereng yang belum sanggup menerima asupan makanan selain ASI.

b. Pelayanan Keluarga Berencana (KB)

Pelaksanaan pada aspek KB dengan melakukan sosialisasi pengenalan macam-macam alat kontrasepsi dan penggunaan KB serta penggunaan $\mathrm{KB}$ gratis untuk menurunkan angka kelahiran.

c. Pelayanan Papsmear dan tes IVA Inspeksi Visual dengan Asam Asetat (IVA) adalah pemeriksaan skrining kanker serviks dengan aplikasi asam asetat (IVA). Dengan metode inspeksi visual yang lebih mudah,

\footnotetext{
${ }^{15}$ Wawancara dengan Ibu Misti, Kader Program MAMPU Desa Sampiran, Pada Senin 02 November 2015.

16 Wawancara dengan Ibu Istiqomah, Ketua Aisyiyah Kota Cirebon, Pada Senin, 02 November 2015.
} 
lebih sederhana, lebih mampu laksana, maka skrining dapat dilakukan dengan cakupan lebih luas, diharapkan temuan kanker serviks dini akan bisa lebih banyak.

d. Jaminan Kesehatan Negara (JKN)

Jaminan Kesehatan

Nasional (JKN) adalah program pemerintah yang bertujuan untuk memberikan kepastian jaminan kesehatan yang menyeluruh bagi seluruh rakyat Indonesia utnuk dapat hidup sehat, produktif dan sejahtera.

Kegiatan tersebut dilakukan dengan cara mensosialisasikan program yang akan dilakukan kepada masyarakat. Tujuannya adalah agar masyarakat dapat memahami maksud dari adanya program MAMPU tersebut. Setelah program tersebut tersosialisasikan kepada masyarakat, pihak Aisyiyah beserta para kader melakukan kegiatan yang telah direncanakan sebelumnya. Kegiatan program yang direncanakan, dilakukan secara bergilir dan masing-masing program yang dilaksanakan menghadirkan ahlinya langsung sesuai dengan program yang akan dilakukan. Hal ini dimaksudkan agar masyarakat bisa terbuka dan bisa menyampaikan keluh kesahnya terkait program tersebut langsung kepada ahlinya.

Program MAMPU Aisyiyah hanya menjangkau 6 desa dari 3 kecamatan yang ada di kabupaten Cirebon, yaitu Kecamatan Talun, Kecamatan Ciledug dan Kecamatan Losari. Salah satu desa yang menjadi sasaran program adalah desa Sampiran, Kecamatan Talun. Program MAMPU terlaksana di desa tersebut pada tahun $2011 .{ }^{17}$ Sebelum program yang telah dicantumkan

${ }^{17}$ Wawancara dengan Ibu Misti, Kader Program MAMPU Desa Sampiran, Pada Selasa, 03 November 2015. terlaksana, terlebih dahulu pihak Aisyiyah bersama masyarakat desa setempat yang menjadi sasaran program mengadakan pertemuan untuk membentuk kader-kader di masing-masing desa sasaran. Kaderkader yang terpilih merupakan masyarakat desa itu sendiri. adapun fungsi dari kader tersebut adalah sebagai koordinator desa sasaran yang akan mengoordinir masyarakat yang menjadi sasaran program tersebut.

Aisyiyah mengusung program MAMPU yang merupakan suatu penguatan kepemimpinan perempuan untuk peningkatan pelayanan kesehatan reproduksi yang lebih terjangkau dengan pendekatan hak-hak perempuan pada kelompok duafa mustadh'afin. Tujuan program MAMPU adalah meningkatkan pemenuhan hak asasi dasar kesehatan reproduksi Perempuan Duafa Mustadh'afin (PDM) ditarget area dalam beberapa aspek yaitu, ASI, pelayanan KB, pelayanan papsmear dan tes IVA, serta JKN. ${ }^{18}$ Strategi yang digunakan melalui pendekatan penguatan kelembagaan, lokal leader, pendidikan, dan pemberdayaan masyarakat.

Banyak hal yang didapatkan oleh masyarakat. Salah satunya masyarakat menjadi sadar bahwa menjaga kesehatan reproduksi itu sangatlah penting. Selain itu, mereka juga menjadi paham tentang macammacam alat $\mathrm{KB}$ dan terkait dengan kesehatan reproduksi lainnya. Adanya program MAMPU tersebut mampu memberikan banyak pengetahuan kepada masyarakat terkait kesehatan reproduksi. Hal ini sangatlah positif untuk dilakukan. Bahkan masyarakat sendiri pun

18 Wawancara dengan Ibu Yanti, Motivator Program MAMPU Desa Sampiran, Pada Senin, 02 November 2015. 
berharap bahwa program ini bisa berjalan secara berkesinambungan. ${ }^{19}$

\section{Kesimpulan}

Berdasarkan beberapa pembahasan di atas, maka dapat diambil kesimpulan bahwa fenomena kematian ibu dan bayi baru lahir serta anak di Kabupaten Cirebon masih menjadi fenomena yang penting untuk mendapat perhatian. Kurangnya akses masyarakat, terutama masyarakat yang dapat dikatakan terpencil, menjadi salah satu penyebabnya. Hal ini menjadi menarik perhatian bagi Forum Peduli KIBBLA untuk ikut andil dalam upaya penekanan angka kematian tersebut. Salah satu program yang dicanangkannya adalah program EMAS dan program MAMPU. Dengan adanya program tersebut, masyarakat mengaku menjadi lebih terbantu, terutama dalam pengetahuan tentang kehamilan. Hal tersebut perlu adanya tindaklanjut supaya program yang dicanangkan dapat berkesinambungan dengan baik.

\section{Daftar Pustaka}

Profil Kesehatan Provinsi Jawa Barat dalam Rencana Strategi Kesehatan Kabupaten Cirebon. Artikel. Cirebon: Dinas Kesehatan. 2014. http://dinkes.cirebonkab.go.id/wpcontent/uploads/Review-Renstra2014-2019.pdf. Diakses Pada Minggu, 22 Juli 2018.

Raji. t.t. Selamatkan Ibu, Sehatkan Anak. Data Skunder. Cirebon: FPKIBBLA.

Sudibyo Alimoesa. 2012. Angka Kematian Ibu, 228/100.000 Kelahiran Hidup. Artikel. Banjarmasin: Kompas. https://tecno.kompas.com. Diakses Pada Minggu, 22 Juli 2018.

http://www.gizikia.depkes.go.id

19 Wawancara dengan Ibu Beda, Salah Satu Warga yang Menerima Program MAMPU Desa Sampiran, Pada Selasa, 03 November 2015. 
